\title{
Applying Positive Discipline in School and Adolescents' Self-esteem
}

\author{
Slađana Zuković1" ${ }^{*}$, Dušica Stojadinović1 \\ ${ }^{1}$ University of Novi Sad, Faculty of Philosophy, Department of Pedagogy, Serbia, \\ e-mail: sladjana.zukovic@ff.uns.ac.rs; dstojadinovic@uns.ac.rs
}

\begin{abstract}
Starting from the general principles of the concept of positive discipline, the paper points out that schools and teachers can significantly contribute to the application of positive discipline to affect different aspects of a student's personality development. The potentials of applying positive discipline in the school for developing adolescents' self-esteem are particularly emphasized. Accordingly, this paper will present the results of a study that aimed to establish a correlation between assessing the presence of positive discipline in a school context and the level of adolescents' self-esteem. The survey included a convenience sample of 195 high school students from three high schools - art, technical, and grammar school. The Rosenberg Self-Esteem Scale and the scale for assessing the presence of positive discipline in the school were used to collect the data. The results showed that adolescents exhibit a high level of self-esteem, while their assessment of the presence of positive discipline in school is moderate. Also, it was found that with the increase in the assessment of the presence of positive discipline in school, the level of adolescents' self-esteem increased, and the statistically significant moderating role of the measured variables was found only in the type of high school. The conclusion points to the need to sensitize teachers to manage the classroom according to the principles of positive discipline, as well as the importance of creating the conditions that, through the phenomenon of positive discipline, effectively raise the quality of schoolwork as a whole.

Keywords: adolescence; positive discipline; self-esteem; school; teachers; students' social competencies.
\end{abstract}

\section{Introduction}

Positive discipline, as an approach to upbringing, is based on the theoretical basis of individual psychology, which considers encouragement as a way of developing self-esteem and reinforcing the belief that the individuals are good enough just the way they are (Adler, 2009). The essential premise of this approach is based on the belief that, in a relationship with children, nothing can be achieved through punishment, threats, and preaching. Instead of this, the child and the adult need to be made aware of what doesn't work in their relationship and how to repair it (Adler, 2009; Nelsen, 1979). Based on this belief, as well as on the integration of knowledge about children's development, children's rights, and effective educational practices, positive discipline becomes a contemporary approach to the upbringing that is based on understanding and respecting the personality of the children, individualized approach and up-bringing by personal example (Durrant, 2013). This creates the basis for the development of personal dignity and self-esteem, respect for other people and respect for their rights, the development of empathy, and the application of non-violent communication (Bej, 2016; Durrant, 2013).

Pointing to the effectiveness of positive discipline in the family and school environment, experts (Bej, 2016; Durrant, 2013; Nelsen, 2007) emphasize that positive discipline offers a system of techniques that help children/youth develop different social skills sustainable in the long-term, self-discipline, and self-confidence when facing real-life situations. It is emphasized that this approach in upbringing and education should be applied in interaction with all children/students, and not only with children/students who are characterized by challenging behavior. Therefore, the paper starts from the view that, besides the family as a basic upbringing factor, the school also represents a very important upbringing environment and that teacher as significant another person can significantly contribute to the application of positive discipline to affect different domains of student personality development, especially during adolescence.

"Corresponding author: sladjana.zukovic@ff.uns.ac.rs 


\section{Applying positive discipline in school - the role of teachers}

Considering the assumptions for the application of positive discipline in school practice, experts (Bej, 2016; Charles and Senter, 2005) emphasize the importance of creating a climate of respect and cooperation that contributes to students perceiving themselves as important and able to control their lives, developing self-control, flexibility and, responsibility. Also, the general school/classroom climate contributes to the development of a sense of belonging to the school, which increases academic success and reduces the risky behaviors of students (Bej, 2016; Uslu and Gizir, 2017).

One of the key assumptions is the role of the teacher, i.e., their competencies and skills for effective application of the principles of positive discipline. Special emphasis is placed on the ability of teachers to control their behavior and reflect on their actions when it comes to upbringing and educational processes (Durrant, 2010; Nelsen, 2007). The essence is that teachers express concern for students, and instead of misrepresenting the logical consequences of behavior through punishment, involve students in solving problems by providing opportunities to see the consequences of their behavior and perceive possible solutions (Burden, 2016).

This mindset and approach to the role of teacher educating are built on four principles: 1) focusing on identifying long-term goals; 2) providing warmth and structure; 3) understanding how children/students think and feel; 4) problem solving and responding with positive discipline (Durrant, 2013). Before applying these principles, teachers must understand them properly and practice their application skills. It is also important that when interacting with the student, they think about long-term goals, ways in which the student can be provided with warmth and structure, and understand why the student behaves in a certain way. The gradual application of these principles can change the way teachers think and act. On the other hand, these principles contribute to the students' acquisition of significant life and social skills (decisionmaking, constructive problem, and conflict resolution, etc.) that will help them become successful members of their community (Chadsey and McVittie, 2006; Durrant, 2013; Nelsen, 2006).

The importance of applying positive discipline for student development is particularly meaningful in adolescence when the influence of the relationships that individuals make outside the family is amplified (Luciana, 2010). In addition to family and peer group, the school is certainly an environment that has a great influence on the development of the individual during adolescence (Oberle, Schonert-Reichl and Zumbo, 2011), with one of the key factors in this development being the relation established in relation teacher-student/adolescent (Demirdag, 2015). In this regard, UNESCO (2006), following the specificity of adolescence, provides some recommendations for teachers to apply positive discipline:

- In the period of early adolescence, the teacher needs to be a role model for mutual respect, which implies the absence of preaching and criticism. Also, it is very important to prevent potential insults and teasing among the students themselves, so it is recommended that students get the opportunity to express their feelings and experiences in different ways.

- In middle adolescence, the recommendations are to encourage students to think creatively and critically. Praise and emphasis on positive behavior are desirable, but also setting reasonable boundaries and clear rules, and consistency in insisting on respecting the. Teachers are also encouraged to share their own beliefs, concerns, and values with students, and to encourage them to turn to adults they respect and trust in situations where they need advice.

- In late adolescence, the recommendations are to encourage discussion on various topics and respect for the uniqueness of each adolescent, because in this way young people learn to respect other people around them, to make decisions independently, and to take responsibility for the consequences of their decisions.

These recommendations on building positive and trust-based relationships between teachers and students open up space for learning and constructive problem solving (Charles and Senter, 2005), create a sense of safety and belonging (Uslu and Gizir, 2017), and help students/adolescents to accept responsibility and take positive control of their behavior in a long-term (Bej, 2016). Such effects are certainly an important potential for the development of adolescents' self-esteem, because, in this period, individuals compare their real and ideal selves, and assess their compliance with social standards and expectations.

\section{esteem}

Potentials of positive discipline in the school for the development of adolescents' self-

The development of self-esteem is a long-term process, which is influenced by many factors, and which goes through periods of decline when moving from one stage of development to another. This process continues even more intensely during adolescence (Papalia and Olds, 1995), especially given that during this period self-esteem levels vary with a tendency to stabilize (Abdel-Khalek, 2016). 
Considering that self-esteem involves beliefs about one's competence, value, and importance, as well as emotional states regarding these (Hewitt, 2009), a high level of self-esteem helps adolescents to meet the challenges that this turbulent period brings. Therefore, it is very important to keep in mind the potential of different educational practices that can contribute to building high self-esteem in adolescents.

In this context, it can be assumed that positive discipline contributes to the building of a positive selfimage in adolescents, because, among other things, it implies an individualized approach and reliance on the positive in the individual's personality. However, there is insufficient research to confirm this hypothesis, in other words, there are no results of research that could surely confirm the effects of positive discipline on the development of self-esteem. One of the key reasons for insufficient empirical confirmation of the abovementioned hypothesis can be considered, first of all, through the limitations that the attempt to measure a person's self-esteem generally carries with it. Experts (Baumeister et al., 2003) state that the main difficulty is that self-esteem is almost exclusively measured by respondents' self-reporting and the fact that there are no objective criteria by which the level of self-esteem that respondents report can be compared. The level of self-esteem examined shows how a person views and evaluates himself/herself, which does not have to coincide with the real level of self-esteem. However, despite these limitations, research into this topic is very valuable, especially when it comes to findings that indicate the potential risks of reduced self-esteem. Thus, for example, research has shown that low self-esteem, especially during adolescence, can have numerous negative consequences: the appearance of depression (Harter, 1986; Rosenberg, 1965), suicide (Kazdin et al., 1983), delinquency (Wells and Rankin, 1983), psychoactive substance use (Stacy, Newcomb and Bentler, 1992); low academic achievement (Hawkins, Catalano and Miller, 1992; Johnston and O'Malley, 1986). Bearing in mind such findings, it is necessary to prevent their occurrence, and the potential benefits of the application of positive discipline during adolescence should not be neglected.

Although examining the effects of applying positive discipline in school is not a widely represented area in empirical research, some research has shown that positive changes in students' behavior (especially when it comes to developing self-esteem during adolescence) can be associated with accepting and applying certain starting points of a positive discipline in a school context. Namely, numerous studies (Furlong et al., 2003; Haynes, Emmons and Ben-Avie,1997; Osterman 2000; Whitlock 2006) have shown that creating positive attitudes and a sense of community in school (as a key starting point for applying positive discipline) serve as protective factors that are positively correlated with adolescent self-esteem, academic achievement, and school adjustment. Also, research (Deci et al., 1981; Demirdag, 2015; Uslu and Gizir, 2017) confirms the importance of the role of teachers in building students' self-esteem, nurturing their independence, and improving their sense of effectiveness in all periods, especially in adolescence. Specifically, it was found that students whose teachers show a greater orientation towards supporting autonomy and individuality (instead of control) also show a higher level of self-esteem. The potential significance of the starting point of positive discipline on the importance of relying on students' capacities, competencies, and talents is supported by research results (Kususanto, Ismail and Jamil, 2010) that the teacher's beliefs about students can be manifested through their behavior that students can detect and which can afterward lead to either increasing or decreasing students' motivation and perception of personal competence.

The above findings indicate the importance of research into this topic because, in addition to contributing to the understanding of the potential of applying positive discipline for the development of student/adolescent self-esteem, they also point to the importance of creating a school ethos that will be sensitized to this approach in upbringing. Within this framework, a draft of the research was designed, the results of which will be presented in the text below.

\section{Materials and Methods}

Goals and objectives of the research. The overall goal of the research was to determine the correlation between the assessment of the presence of positive discipline in the school context and the level of adolescents' self-esteem. Based on the set goal, the following research objectives were formulated: 1. To examine the adolescents' assessment of the presence of positive discipline in the school, and whether there are differences in assessment depending on the gender of the adolescents and the type of school; 2. To examine the level of adolescents' self-esteem, and whether there are differences in the level depending on the gender and academic achievement of adolescents; 3 . Examine the nature of the correlation between the assessment of the presence of positive discipline in school and the level of adolescents' self-esteem, and to what extent the assessment of the presence of positive discipline in 
school explains the level of adolescents' self-esteem; 4. Examine the moderating role of gender, high school type, and academic achievement in the relationship between assessing the presence of positive discipline in school and the level of adolescents' self-esteem.

Measurements and variables. Two instruments were used to achieve the set research goal:

- Rosenberg's Self-Esteem Scale (RSES) (Rosenberg, 1965), despite general limitations in measuring self-esteem, showed high levels of validity and reliability (according to Robins, Hendin and Trzesniewski, 2001), which was also confirmed at the sample level in our study (Kronbach's alpha is .867). The scale has ten items, using a five-point Likert-type scale (from 1- I disagree to 5 - strongly agree), which in some earlier studies (Leung, 2011) found very similar basic psychometric characteristics as the original four-point scale.

- The scale for assessing the presence of positive discipline in the school was constructed for this research, based on the study of the theoretical basis and characteristics of positive discipline outlined by Jane Nelsen (Nelsen, 2007). The scale consisted of ten items that are related to key principles of the application of positive discipline by teachers: 1 ) the principle of focusing on long-term goals in upbringing: (Teachers help me to understand the consequences of my behavior and to develop responsibility for them; Teachers strive to help me to learn something meaningful for everyday life in each unit; Teachers remain consistent and stick to everything they promise); 2) the principle of providing warmth and structure (Teachers are interested in my feelings, not just knowledge and school life; teachers are not interested to understand explanations and reasons for my actions); 3 ) the principle of individualized approach and reliance on the positive in personality (Teachers praise the effort I put in; Teachers explain each grade they give me; Teachers strive to value my knowledge, interest, and commitment that I show); 4) the principle of problem-solving and responding with positive discipline (Teachers strive to understand the situation I am in or the mistake I make; Teachers are not ready to find a compromise and help to jointly resolve the situation or problem I find myself in). The answers were expressed in the form of a five-point Likert-type scale (1-never, 2-rarely, 3-sometimes, 4-almost always, 5-always), and the analysis determined that it was a one-factor scale showing satisfactory metric characteristics (Kronbach's alpha amounts to .788).

The following variables were used: independent variable (adolescents' assessment of the presence of positive discipline at school); dependent variable (adolescents' self-esteem); extraneous variables (sex, school achievement, high school type). In analyzing the data collected, and to accomplish the set objectives, for certain variables (sex, school achievement, and high school type) their moderating role is analyzed in the relationship between independent and dependent variables.

Sample and statistical procedures. The study involved 195 high school grade students from three high schools in Novi Sad, in the Republic of Serbia. Sample included $97(49.7 \%)$ male and $98(50.3 \%)$ female respondents. The number of students from Art highs school we included in this study was 64 $(32.8 \%), 78$ students from grammar school $(27.2 \%)$, and 53 students from Technical high school $(40 \%)$. When it comes to school achievement the sample consisted of 108 students with excellent $(55.4 \%), 66$ with very good $(33.8 \%), 18$ with good $(9.2 \%)$, and $3(1.5 \%)$ students with sufficient school achievement. In the study conducted there were no students with poor academic achievement.

For the statistical analysis of the data, it was used SPSS package and within it the descriptive statistics procedures (determination of the normality of distribution of the collected data, determination of the reliability of the instruments, t-test of independent samples, ANOVA, correlation, regression, and moderation PROCESS analysis).

\section{Results}

The research results will be presented according to the research objectives under the set research framework. The first research objective was to determine the presence of positive discipline in school, as assessed by adolescents. At the level of the entire scale for assessing the presence of positive discipline, the arithmetic mean is 29.94 ( $\min =12$, $\max =44$ ). Given that the scale used is not standardized, it is not possible to conclude on the level of assessment of the presence of positive discipline. Nevertheless, based on the arithmetic value of the scale that is in the second half of the distribution, it can be concluded that adolescents evaluate the use of positive discipline as moderately present. The resulting descriptive statistics values for each item are shown in Table 1. 
Table 1

The scale of assessment of the presence of positive discipline in schools

\begin{tabular}{llccc}
\hline \multicolumn{1}{c}{ Item } & Min & Mean & Max \\
\hline 1. Teachers are interested in my feelings, not just knowledge and school & 1 & 1.99 & 5 \\
life. & & & \\
2. Teachers make an effort to understand the situation I am in or the mis- & 1 & 2.44 & 5 \\
take I make. & & & \\
3. Teachers are not interested in the explanation and reasons for my ac- & 1 & 3.03 & 5 \\
$\quad$ tions. & 1 & 3.23 & 5 \\
4. Teachers are not ready to find a compromise and jointly resolve a situ- & 1 & & \\
$\quad \begin{array}{l}\text { ation or problem that I find myself in. } \\
\text { 5. Teachers explain each grade I get. }\end{array}$ & 1 & 3.30 & 5 \\
6. Teachers remain consistent and stick to everything they promise. & 1 & 3.25 & 5 \\
7. Teachers strive to value my knowledge, interest, and commitment that I & 1 & 3.50 & 5 \\
$\quad$ show. & 1 & 3.22 & 5 \\
8. Teachers praise the effort I put in. & 1 & 2.91 & 5 \\
9. Teachers help me understand the consequences of my behavior and & & & \\
$\quad$ develop responsibility for them. & 1 & 3.02 & 5 \\
10. Teachers do their best to help me learn something meaningful for eve- & 1 & & \\
\hline
\end{tabular}

In order to examine differences in adolescent's assessment of the presence of positive discipline concerning the type of high school, one-factor analysis of variance was conducted (Table 2). The results showed that there were no statistically significant differences in the assessment of the presence of positive discipline, depending on the type of high school students attend.

Table 2

Applying positive discipline and the type of high school

\begin{tabular}{lccccc}
\hline & N & Mean & SD & F & p \\
\hline Art school & 64 & 28.92 & 6.03 & & \\
Technical school & 53 & 29.73 & 7.21 & 1.25 & .84 \\
Grammar school & 78 & 30.92 & 5.56 & & \\
\hline Total & 195 & 29.94 & 6.23 & & \\
\hline
\end{tabular}

To examine differences in the assessment of the presence of positive discipline in school concerning the sex of adolescents, a t-test of independent samples was conducted. The results obtained (Table 3) show that female adolescents are more likely to perceive the presence of positive discipline in school than male adolescents, but the difference in assessment is not statistically significant.

Table 3

Applying positive discipline and the sex of adolescents

\begin{tabular}{|c|c|c|c|c|c|c|}
\hline & Sex & $\mathrm{N}$ & Mean & $\mathrm{SD}$ & $\mathrm{t}$ & $\mathrm{p}$ \\
\hline \multirow{2}{*}{ Applying positive discipline in school } & Male & 97 & 29.06 & 6.27 & \multirow{2}{*}{-1.86} & \multirow{2}{*}{.06} \\
\hline & Female & 98 & 30.71 & 6.11 & & \\
\hline
\end{tabular}

The second research objective was to determine adolescents' self-esteem levels. An arithmetic means of 38.07 ( $\min =14, \max =50$ ) indicates that the adolescents surveyed exhibit a high level of self-esteem. By examining differences in adolescents' self-esteem levels concerning adolescent sex, no statistically significant differences were found (Table 4). 
Zuković, S. \& Stojadinović, D. (2021). Applying positive discipline in school and adolescents' self-esteem, International Journal of Cognitive Research in Science, Engineering and Education (IJCRSEE), 9(1), 1-11.

Table 4

Self-esteem and the sex of adolescents

\begin{tabular}{lcccccc}
\hline \multirow{2}{*}{ Self-esteem } & Sex & N & Mean & SD & t & p \\
& Male & 97 & 38.31 & 8.06 & \multirow{2}{*}{43} & \multirow{2}{*}{66} \\
& Female & 98 & 37.82 & 7.79 & & \\
\hline
\end{tabular}

By examining differences in adolescents' self-esteem levels concerning school achievement, onefactor analysis of variance revealed statistically significant differences (Table 5). The arithmetic means values indicate that adolescents with better school achievement also exhibit higher levels of self-esteem.

Table 5

Self-esteem and adolescents' school achievement

\begin{tabular}{lccccc}
\hline & N & AS & SD & F & $p$ \\
\hline Sufficient & 3 & 28.66 & 5.50 & & \\
Good & 18 & 35.88 & 9.30 & 3.32 & .02 \\
Very good & 66 & 37.00 & 8.34 & & \\
Excellent & 108 & 39.35 & 7.16 & & \\
\hline Total & 195 & 38.07 & 7.91 & & \\
\hline
\end{tabular}

The third research objective was to examine the correlation between assessing the presence of positive discipline in school and adolescent's self-esteem. To this end, the Pearson linear correlation coefficient was applied, and the values obtained are shown in Table 6.

Table 6

Correlation between applying positive discipline in schools and the adolescents' self-esteem

\begin{tabular}{lccc}
\hline & $\begin{array}{c}\text { Applying positive discipline } \\
\text { in schools }\end{array}$ & $\begin{array}{c}\text { Adolescents' } \\
\text { self-esteem }\end{array}$ & $\mathrm{p}$ \\
\hline Applying positive discipline in schools & 1 & .32 & .00 \\
Adolescents' self-esteem & .32 & 1 & .00 \\
\hline
\end{tabular}

The statistical analysis conducted confirmed the existence of a statistically significant and positive correlation between the assessment of the presence of positive discipline in school and the level of adolescents' self-esteem. The results show that with the increase in the assessment of the presence of positive discipline at school, the level of adolescents' self-esteem also increases.

To see the extent to which the assessment of the presence of positive discipline at school explains the level of adolescents' self-esteem, a regression was performed (Table 7). The assessment of the presence of positive discipline in school was found to explain $9.8 \%$ of the adolescent self-esteem variable.

Table 7

Regression - the extent to which the assessment of the presence of positive discipline at school explains the level of adolescents' self-esteem

\begin{tabular}{lllll}
\hline & $\mathrm{R}$ & $\mathrm{R} 2$ & Kor. R & $\mathrm{p}$ \\
\hline Applying of positive discipline in schools & .312 & .098 & .093 & .00
\end{tabular}

The fourth research objective was to determine the moderating role of sex, school achievement, and type of high school. Therefore, process analysis of the interaction of these variables, and their impact on the relationship between the assessment of the presence of positive discipline in school and the level of adolescents' self-esteem was made. A model that included a variable for assessing the presence of positive discipline in school and adolescents' sex turned out to be statistically significant $(F(3,191)=7.33$; $p<0.01 ; R 2=.10)$. Regarding the moderator role of sex, no statistical significance was found $(b=5.36$; $t(191)=-.46 ; p=.64)$. A model that included a variable for assessing the presence of positive discipline in school and adolescents' school achievement turned out to be statistically significant $(F(3,191)=9.19$; 
$p<0.01 ; R 2=.12)$ but no statistical significance was found in examining the moderating role of school achievement $(b=6.15 ; t(191)=1.91 ; p=0.056)$. A model that included the positive discipline presence assessment variable and high school type proved to be statistically significant $(F(3,191)=10.16 ; p<0.01$; $\mathrm{R} 2=.13)$. In examining the moderator role of the high school type, statistical significance was found ( $b=$ $8.17 ; t(191)=2.48 ; p=0.01)$. Table 8 shows the results of the moderator role concerning the type of high school.

Table 8

Moderator role of the type of high school

\begin{tabular}{lcccccc}
\hline & $\mathrm{b}$ & $\mathrm{se}$ & $\mathrm{t}$ & $\mathrm{p}$ & $\mathrm{LLCl}$ & $\mathrm{ULCl}$ \\
\hline Art school & .60 & .13 & 4.32 & .00 & .3275 & .8770 \\
Technical school & .37 & .08 & 4.32 & .00 & .2031 & .5432 \\
Grammar school & .14 & .13 & 1.05 & .29 & -.1260 & .4140 \\
\hline
\end{tabular}

An insight into Table 8 shows that a statistically significant moderating role of the assessment of the application of positive discipline exists in art and technical school. It can also be observed that with the increase of one unit of assessment of the presence of positive discipline in art school, adolescents' self-esteem increases by .60 , and that with the increase of one unit of assessment of the presence of positive discipline in technical school adolescents' self-esteem increases by .37. grammar school students showed that a higher assessment of the presence of positive discipline was not statistically significant for the change in adolescents' self-esteem.

\section{Discussion}

Based on the results of the adolescent assessment of the presence of positive discipline in school, it is possible to see that items related to the application of the principles of positive discipline (such as consistency and focus on problem-solving, reliance on positive and long-term goals) are assessed at a high level. On the other hand, adolescents believe that respect for desires and feelings, i.e., providing warmth and structure as an important principle of applying positive discipline in the school context, is the least present. Although in the relevant literature (Nelsen, 2007) the individualized approach is emphasized as a key aspect of positive discipline, the findings obtained at the level of our sample show that it is the least present. The importance of applying an individualized approach, especially when working with adolescents, is emphasized by the results of other research (Ames and Miller, 1994; Deci et al., 1982; Demirdag, 2015) which indicate that teachers who know each of their students, respect their needs, support their autonomy, value and respect their personality as a whole, and positively influence the intrinsic motivation and self-esteem of students. Also, research (Deci et al., 1982; Demirdag, 2015) has shown that controlling behavior in relationships with students, i.e., the authoritarian approach as a classroom management strategy, has a limited positive impact on adolescent personality. In line with the above, the findings obtained at the level of our sample may indicate a tendency for teachers to practice a more directive style of communication, which contradicts the basic postulates of positive discipline and individualized approach, which include non-directive communication style, and the use of praise, encouragement, and acceptance of students' ideas.

When it comes to the type of school, the results showed that adolescents surveyed in all three high schools evaluate the application of positive discipline at a similar level. This result may indicate that, regardless of the type of high school, teachers prefer a certain style of behavior and form of communication that may be in a certain relationship with a more or less assessed level of application of positive discipline. Therefore, a proposal for further research would be to analyze the relationship that exists between teacher behavior styles and the level of application of positive discipline. Also, the obtained findings indicate an equally important need to improve the pedagogical competencies of teachers in both grammar school and secondary vocational schools.

When it comes to the results related to the self-esteem variable, it was shown that the examined adolescents express a high level of self-esteem. This finding can be related to the tendency of self-esteem to stabilize in this period, which Rosenberg confirmed in his research (according to Tashakkori et al., 1990). The relevant literature (Dumont and Provost, 1999; Tashakkori et al., 1990) points out that the presence of high levels of adolescent self-esteem can be associated with a more positive interpretation of everyday circumstances, changes, and stress that adolescents face in this unstable period of development 
but also with experiencing more positive situations and experiences in everyday life. Interestingly, some researchers (Thorne and Michaelieu, 1996) found a difference in the level of self-esteem of adolescents in favor of male adolescents, which they explained by the premise that self-esteem in adolescence is based primarily on perceptions of the individual about his/her body and appearance, which have in mind the social pressures and the image of the woman that exists in modern society, as well as the faster physical maturation of adolescents, can cause lower levels of self-esteem in female adolescents. Similarly, other researchers (Robins et al., 2002; Zeigler-Hill and Myers, 2012) have pointed to differences in selfesteem in favor of male adolescents, and that this difference remains noticeable during early and middle adolescence, after which decreases and disappears at a later age. The results of our study showed results in self-esteem in favor of male adolescents, but not at a statistically significant level, which may be due to a small sample of respondents.

The analysis related to determining the differences in the level of self-esteem of adolescents concerning school achievement showed that adolescents with better school achievement also express a higher level of self-esteem. However, this result should be taken with a reservation, having in mind the uneven distribution of the sample according to school success, but also the difficulties in clearly understanding the cause-and-effect relations of these two variables. Namely, numerous studies (Baumeister et al., 2003) have confirmed a positive correlation between school achievement and self-esteem, but at different levels of strength. Some authors (Hansford and Hattie, 1982) found that there was a statistically significant and positive correlation between school achievement and self-esteem, and regression found that self-esteem explains between $4 \%$ and $7 \%$ of the school achievement variable. Also, research (Baumeister et al., 2003; Manning, 2007) has found that better school achievement leads to higher levels of self-esteem, ie that high self-esteem is the result, not the cause of good school achievement. All the above points to a positive correlation between these two variables, but also to their complex and ambivalent relationship, which makes it more difficult to interpret the research results more precisely.

When it comes to examining the relationship between the predictor and criterion variable, it was found that with the increase of assessment of the presence of positive discipline, the adolescent's selfesteem potentially grows. This is supported by the results of previous research (Demirdag, 2015) which showed that if teachers set high expectations, rely on the positive in adolescence, are focused on longterm goals, and are consistent in their actions, can positively affect adolescents' self-esteem. The claims related to these aspects of the application of positive discipline in school were the ones that were assessed as the most present by the surveyed adolescents.

By applying process analysis, a statistically significant moderator role of the high school type was found. An interesting finding is that in secondary vocational schools it has been shown that adolescents' self-esteem grows if the assessment of the presence of positive discipline also grows. On the other hand, the respondents from grammar high school showed stability of self-esteem, regardless of the assessment of the presence of positive discipline. This situation may be a consequence of the already built experience of academic self-efficacy in grammar high school students, which is also reflected in their experience of self-worth (Gutvajn and Džinović, 2019). In any case, the obtained findings imply the need for further research on the relationship between the specifics of the school environment (dimensions of school climate, educational style of teachers) and personal characteristics of students (personality traits, academic self-concept, goal orientation, etc.) that may be important for their self-esteem development.

\section{Limitations and recommendations for further research}

Although the findings provide a good starting point for considering the possibility of improving positive discipline in schools in Serbia, it is important to mention the limitations of the research as well as recommendations for further research on this topic. The key limitation refers to the sample of respondents because it is a convenient sample that prevents the generalization of the results of the research to a wider population of students. Another limitation regarding the sample of respondents is the inhomogeneous distribution of respondents concerning school achievement, and because of that the results of the analysis according to this variable must be taken with a reservation. Also, it is necessary to keep in mind that in this research, only the perspective of adolescents is presented, which can make it difficult to draw conclusions about the real representation of positive discipline in schools. Accordingly, future research on this topic should include teachers' perspectives on the importance and effects of applying positive discipline, as well as their self-assessment of dominant educational procedures and classroom management strategies. In addition to all the above, in further research on this topic, it would be desirable to apply some other research methods (such as systematic observation, interviewing, focus group examination) that would provide a more accurate image of the researched subject. 


\section{Conclusion}

Generally speaking, the results of the presented research point to the conclusion that the application of positive discipline in the school environment can be viewed as a significant potential for strengthening the self-esteem of students/adolescents. On the other hand, we should not ignore the finding that, according to the respondents, teachers insufficiently apply the principles of the individualized approach, providing warmth and structure, as well as relying on the positive in the personality of students. In this sense, the key practical implication of the findings relates to the need for teachers to master strategies for effective classroom management (Demirdag, 2015; Uslu and Gizir, 2017), because such teacher competencies are important for the effective application of positive discipline, and therefore for the development of adolescent self-esteem.

It is also important to emphasize that the potential benefits of applying positive discipline for the development of students '/ adolescents' self-esteem should be viewed as an important resource for preventing various forms of undesirable behavior and thus for creating school as a safe environment (McVittie, 2003; Osher et al., 2010). Particular emphasis is placed on the positive effects of combining two approaches to improving school discipline - Support for Positive School Behavior (SBPBC) which aims to develop a student behavior management system and Social-Emotional Learning (SEL) which aims to develop resources for student self-discipline (according to Osher et al., 2010). Although these approaches differ in their primary goals, what they have in common is that they are aimed at preventing problematic behavior and promoting students' social competencies.

Given that self-esteem is a significant protective factor in preventing antisocial behaviors (Dobrescu, 2013), the school's task is to allow each student to develop their potential and grow up in a climate of appreciation and respect (Bej, 2016; Gutvajn and Džinović, 2019). Therefore, it would be desirable to focus on the development of professional competencies, not only teachers but also all actors in school life, in order to create conditions to effectively raise the quality of schoolwork as a whole through the phenomenon of positive discipline. Finally, the importance of family/parent involvement should not be left out (McVittie, 2003; Uslu and Gizir, 2017), as well as the importance of harmonizing parenting style and teaching style (Paulson, Marchant, and Rothlisberg, 1998), having in mind that an authoritative style is recommended as a starting point for effective applying positive discipline in both family and school (Nelsen, 2006). In that sense, it is very important to nurture such a cooperative relationship between families and schools that will contribute to the application of the principles of positive discipline in both developmental environments to maintain continuity in educational procedures towards children/students.

\section{Acknowledgements}

This paper was written within the project "Quality of educational system of Serbia in the European perspective" (179010) and "Pedagogical Pluralism as the Basis of Education Strategy (179036), financed by the Ministry of Education, Science and Technological Development of the Republic of Serbia.

\section{Conflict of interests}

The authors declare no conflict of interest.

\section{References}

Abdel-Khalek, A. (2016). Introduction to the Psychology of self-esteem. In F. Holloway (Ed.), Self-esteem: perspectives, influences, and improvement strategies (pp. 1-23). New York: Nova Science Publishers.

Adler, A. (2009). Understanding life: An introduction to the Psychology of Alfred Adler. UK: Oneworld.

Ames, N. L., \& Miller, E. (1994). Changing middle schools, how to make schools work for young adolescents. California: Jossey-Bass Publishers.

Baumeister, R. F., Campbell, J. D., Krueger, J. I., \& Vohs, K. D. (2003). Does High Self-Esteem Cause Better Performance, Interpersonal Success, Happiness, or Healthier Lifestyles. Psychological Science in the Public Interest 4(1), 1-44. https://doi.org/10.1111\%2F1529-1006.01431

Bej, M. (2016). Social Skills and Programs of Positive Discipline in School Environment - A Literature Review. Mediterranean Journal of Social Sciences, 7(2 S1), 84-87. http://dx.doi.org/10.5901/mjss.2016.v7n2s1p84

Burden, P. (2016). Classroom Management: Creating a Successful K-12 Learning Community. New York: John Wiley \& Sons.

Chadsey, T., \& McVittie, J. (2006). The Positive Discipline School. Positive Discipline Association. Retrieved from: https:// positivediscipline.org/resources/Documents/PDSbrchr-8-06.pdf

Charles, C. M., \& Senter, G. W. (2005). Building classroom discipline. Boston: Pearson.

Deci, E. L., Schwartz, A. J., Sheinman, L., \& Ryan, R. M. (1981). An Instrument to assess adults' orientations toward control 
Zuković, S. \& Stojadinović, D. (2021). Applying positive discipline in school and adolescents' self-esteem, International Journal of Cognitive Research in Science, Engineering and Education (IJCRSEE), 9(1), 1-11.

versus autonomy with children: Reflexion on intrinsic motivation and perceived competence. Journal of Educational Psychology, 73(5), 642-650. https://doi.org/10.1037/0022-0663.73.5.642

Deci, E. L., Spiegel, N. H., Ryan, R. M., Koestner, R., \& Kauffman, M. (1982). Effects of performance standards on teaching styles: Behavior of controlling teachers. Journal of Educational Psychology, 74(6), 852-859. https://doi.org/10.1037/00220663.74.6.852

Demirdag, S. (2015). Classroom management and students' self-esteem: Creating positive classrooms. Educational Research and Reviews, 10(2), 191-197. https://doi.org/10.5897/ERR2014.2000

Dobrescu, A. (2013). Adolescent self-esteem. Bulletin of the Transilvania University of Braşov, Series VII: Social Sciences and Law, (2), 139-144.

Dumont, M., \& Provost, M. A. (1999). Resilience in adolescents: Protective role of social support, coping strategies, selfesteem, and social activities on experience of stress and depression. Journal of Youth and Adolescence, 28(3), 343363. https://doi.org/10.1023/a:1021637011732

Durrant, J. E. (2010). Positive discipline in everyday teaching: Guidelines for educators. Save the Children Sweden.

Durrant, J. E. (2013). Positive discipline in everyday parenting. Ottawa, ON: Save the Children Sweden.

Furlong, M. J., Whipple, A. D., Jean, G. S., Simental, J., Soliz, A., \& Punthuna, S. (2003). Multiple contexts of school engagement: Moving toward a unifying framework for educational research and practice. The California School Psychologist, 8(1), 99-113. https://doi.org/10.1007/bf03340899

Gutvajn, N., \& Džinović, V. (2019). Identitet neuspešnog učenika. [The identity of an unsuccessful student]. Belgrade: Institute for Pedagogical Research.

Hansford, B. C., \& Hattie, J. A. (1982). The relationship between self and achievement/performance measures. Review of Educational Research, 52(1), 123-142. https://doi.org/10.3102/00346543052001123

Harter, S. (1986). Cognitive-developmental processes in the integration of concepts about emotions and the self. Social cognition, 4(2), 119-151. https://doi.org/10.1521/soco.1986.4.2.119

Hawkins, J. D., Catalano, R. F., \& Miller, J. Y. (1992). Risk and protective factors for alcohol and other drug problems in adolescence and early adulthood: Implications for substance abuse prevention. Psychology Bulletin, 112(1), 64-105. https://doi.org/10.1037/0033-2909.112.1.64

Haynes, N. M., Emmons, C., \& Ben-Avie, M. (1997). School climate as a factor in student adjustment and achievement. Journal of Educational and Psychological Consultation, 8(3), 321-329. https://doi.org/10.1207/s1532768xjepc0803_4

Hewitt, J. P. (2009). Oxford Handbook of Positive Psychology. Oxford: Oxford University Press.

Johnston, L. D., \& O'Malley, P. M. (1986). Why do the nation's students use drugs and alcohol: Self-reported reasons from nine national surveys. Journal of Drug Issues 16(1), 29-66. https://doi.org/10.1177/002204268601600103

Kazdin, A. E., French, N. H., Unis, A. S., Esveldt-Dawson, K., \& Sherick, R. B. (1983). Hopelessness, depression, and suicidal intent among psychiatrically disturbed inpatient children. Journal of consulting and clinical psychology, 51(4), 504-510. https://doi.org/10.1037/0022-006x.51.4.504

Kususanto, P., Ismail, H. N., \& Jamil, H. (2010). Students' self-esteem and their perception of teacher behavior: A study of between-class ability grouping. Electronic Journal of Research in Educational Psychology, 8(2), 707-724. https://doi. org/10.25115/ejrep.v8i21.1395

Leung, S. O. (2011). A comparison of psychometric properties and normality in 4-, 5-, 6-, and 11-point Likert scales. Journal of Social Service Research, 37(4), 412-421. https://doi.org/10.1080/01488376.2011.580697

Luciana, M. (2010). Adolescent brain development: Current themes and future directions. Introduction to the special issue. Brain and Cognition, 72(1), 1-5. https://doi.org/10.1016/j.bandc.2009.11.002

Manning, M. A. (2007). Self-concept and self-esteem in adolescents. Student services, 2, 11-15. Retrieved from: https://www. semanticscholar.org/paper/Self-Concept-and-Self-Esteem-in-Adolescents-Manning/5367523293360cf1fd39a4da7a7f $4 \mathrm{e} 7 \mathrm{e} 27 \mathrm{bfcbaa}$

McVittie, J. (2003). Research Supporting Positive Discipline in Homes, Schools, and Communities. Positive Discipline Association. Retrieved from: https://positivediscipline.org/resources/Documents/ ResearchSupportingPositiveDisciplineinHomesSchoolsandCommunities.pdf

Nelsen, J. (1979). The effectiveness of Adlerian parent and teacher study groups in changing child maladaptive behavior in a positive direction. University of San Francisco, San Francisco, California. Retrived from: https://positivediscipline.org/ resources/Documents/TheEffectivenessOfAdlerianParentandTeacherStudyGroups.pdf

Nelsen, J. (2006). Positive Discipline: The Classic Guide to Helping Children Develop Self-Discipline, Responsibility, Cooperation, and Problem-Solving Skills. New York: Ballantine Books.

Nelsen, J. (2007). Cómo educar con firmeza y cariño: disciplina positiva. [How to educate with firmness and kindness: Positive discipline]. Barcelona: Médici.

Oberle, E., Schonert-Reichl, K. A., \& Zumbo, B. D. (2011). Life satisfaction in early adolescence: Personal, neighborhood, school, family, and peer influences. Journal of youth and adolescence, 40(7), 889-901. https://doi.org/10.1007/s10964010-9599-1

Osher, D., Bear, G. G., Sprague, J. R., \& Doyle, W. (2010). How can we improve school discipline? Educational researcher, 39(1), 48-58. https://doi.org/10.3102/0013189X09357618

Osterman, K. F. (2000). Students' need for belonging in the school community. Review of educational research, 70(3), 323-367. https://doi.org/10.3102/00346543070003323

Papalia, E. D., \& Olds, W. S. (1995). Human development $5^{\text {th }}$ edition. New York: Mcgraw-Hill College.

Paulson, S. E., Marchant, G. J., \& Rothlisberg, B. A. (1998). Early adolescents' perceptions of patterns of parenting, teaching, and school atmosphere: Implications for achievement. The Journal of Early Adolescence, 18(1), 5-26.

Robins, R. W., Trzesniewski, K. H., Tracy, J. L., Gosling, S. D., \& Potter, J. (2002). Global self-esteem across the life span. Psychology and aging, 17(3), 423-434. https://doi.org/10.1037/0882-7974.17.3.423

Robins, R. W., Hendin, H. M., \& Trzesniewski, K. H. (2001). Measuring global self-esteem: Construct validation of a single-item measure and the Rosenberg Self-Esteem Scale. Personality and social psychology bulletin, 27(2), 151-161. https:// doi.org/10.1177/0146167201272002

Rosenberg, M. (1965). Society and the adolescent self-image. Princeton, NJ: Princeton University Press. 
Stacy, A. W., Newcomb, M. D., \& Bentler, P. M. (1992). Interactive and higher-order effects of social influences on drug use. Journal of Health and Social Behaviour. 33(3), 226-241. https://doi.org/10.2307/2137353

Tashakkori, A., Thompson, V. D., Wade, J., \& Valente, E. (1990). Structure and stability of self-esteem in late teens. Personality and individual differences, 11(9), 885-893. https://doi.org/10.1016/0191-8869(90)90268-v

Thorne, A., \& Michaelieu, Q. (1996). Situating adolescent gender and selflesteem with personal memories. Child Development, 67(4), 1374-1390. https://doi.org/10.2307/1131706

Unesco (2006). Positive discipline in the inclusive, learning-friendly classroom: a guide for teachers and teacher. Retrieved from: https://unesdoc.unesco.org/ark:/48223/pf0000149284

Uslu, F., \& Gizir, S. (2017). School Belonging of Adolescents: The Role of Teacher-Student Relationships, Peer Relationships and Family Involvement. Educational sciences: theory \& practice, 17(1), 63-82. https://doi.org/10.12738/estp.2017.1.0104

Wells, E. L., \& Rankin, J. H. (1983). Self-concept as a mediating factor in delinquency. Social Psychology Quarterly 46(1), 1122. https://doi.org/10.2307/3033656

Whitlock, J. L. (2006). Youth perceptions of life at school: Contextual correlates of school connectedness in adolescence. Applied Developmental Science, 10(1), 13-29. https://doi.org/10.1207/s1532480xads1001_2

Zeigler-Hill, V., \& Myers, E. M. (2012). A review of gender differences in self-esteem. In S. P. McGeown (Ed.). Psychology research progress. Psychology of gender differences (pp. 131-143). Hauppauge, NY, US: Nova Science Publishers. 
